\title{
A RARE SPIDER
}

\section{By Elizabeth B. BRyant}

Museum of Comparative Zoölogy, Cambridge, Mass.

Among a collection of spiders from Dallas, Texas, sent to the Museum of Comparative Zoölogy this spring was a small spider which proved to be Prodidomus rufus Hentz, a species that has not been found for many years.

Hentz found a single female (?) "in a large box in a dark cellar," August 10th. The arrangement of the eyes was so unusual that he made a new genus for it and placed it near Callopodia (= Hyptiotes). As far as known an adult has never been found since. In the summer of $1891 \mathrm{Mr}$. Banks found a few immature specimens in a house at Shreveport, Louisiana, and because they were so unusual he described and figured them in the Proc. Ent. Soc. Washington, 1892, 2, p. 259, fig. 12.

In 1918, Compte de Dalmas made a revision of the family Prodidomidæ in the Ann. Soc. Ent. France, 87, pp. 279340 with numerous figures. He had use of the large collection of M. Simon which contained most of the known species but Prodidomus rufus Hentz, the genotype, was known by the very brief original description and the one given by Mr. Banks for the immature specimens. Because of certain discrepancies Dalmas suggests that the two may be separate species. This is probably doubtful because the difference in color can easily be explained by age or general conditions, such as moisture and food and the size of the eyes by the inadequate facilities of lighting and magnification used by naturalists nearly a century ago.

This specimen from Texas is adult and was found out of doors probably on the ground instead of in a house or cellar and the abdomen is only tinged with pink, not red as described by Hentz. It also differs in two characters from others in the genus, the a.m.e. are distinctly the largest of the eight, the fourth trochanter is no longer 
than the coxa instead of the longest. These differences would indicate that Miltia Simon is a distinct genus as Dalmas suggests.
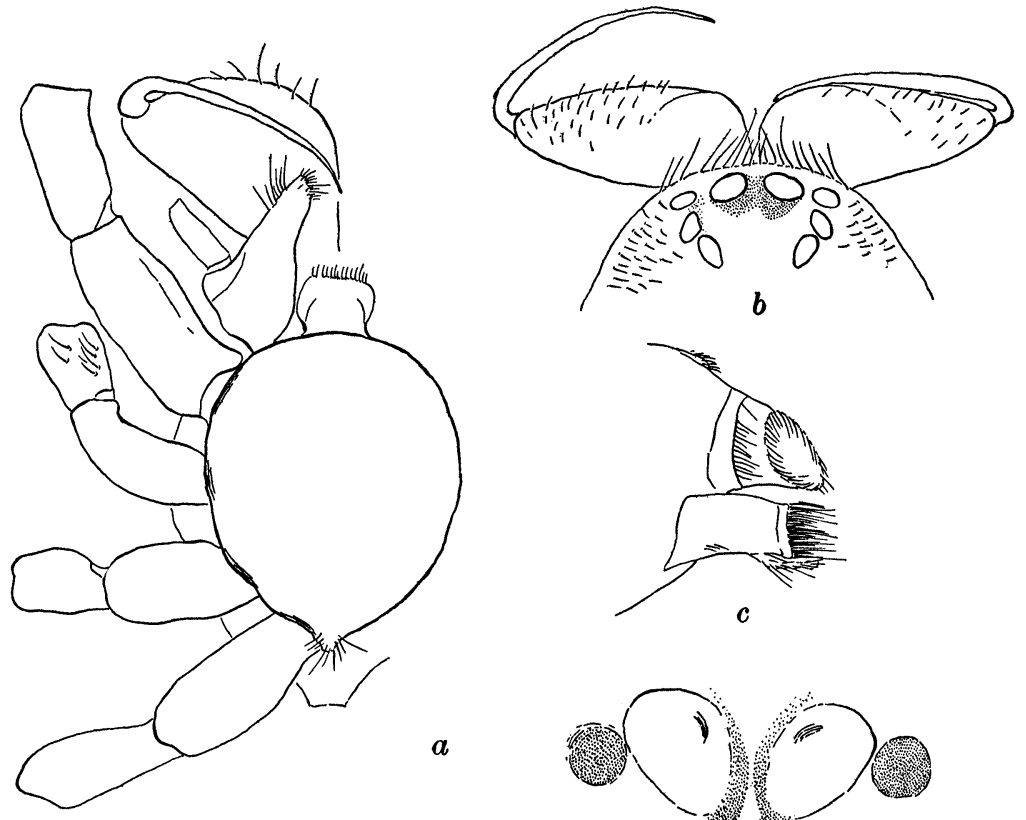

$b$
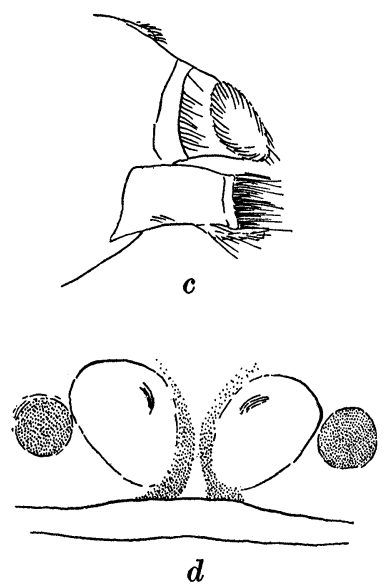

Fig. 1. Prodidomus rufus Hentz. a, ventral view of carapace; $b$, eyes and cheliceræ; $c$, lateral view of spinnerets; $d$, epigynum.

\section{Prodidomus rufus Hentz (Fig. 1)}

Journ. Boston Soc. Nat. Hist., 1847, 5, p. 466, pl. 30, fig. 4 ; reprint, 1875 , p. 105 , pl. 12 , fig. 4 , pl. 18 , fig. 9 . ․ $5 \mathrm{~mm}$. long, ceph. 2. mm., abd. $3.1 \mathrm{~mm}$.

Cephalothorax pale yellow, sides with long scattered hairs directed towards the center, rather low and flat, no thoracic groove or separation of cephalic and thoracic portion, sides evenly rounded, anterior margin wider than posterior and slightly rounded; eyes eight, a.m.e. only diurnal, round and dark, other eyes white, flat and angular, anterior row straight by upper margins, a.m.e. largest of the eight, 
separated by less than a radius and from a.l.e. by a little more, posterior row so strongly procurved that with the a.l.e., the p.l.e. and p.m.e. form a converging row, p.m.e. widely separated; quadrangle of median eyes narrower in front and higher than wide; clypeus less than diameter of a.m.e., slightly convex with a thin fringe of long hairs on margin; mandibles yellow with stiff colorless hairs, swollen at basal third, and widely divergent, so that fang groove has greater width than the cephalothorax, no boss, fang groove long and poorly defined, no teeth on either margin, fang long, slender and abruptly bent at origin; labium pale yellow, about as long as wide, tip truncate, slightly narrower than base, margins not rebordered, distinct suture between sternum; maxillæ twice as long as labium, origin of pedipalp below middle, distal half much attenuate and slightly inclined over labium; pedipalp lacking claw and terminal joint truncate; sternum pale yellow, darker about margin, smooth, flat and oval, two-thirds as wide as long, widest between second coxæ; ending in a small, obtuse, hairy lobe between fourth coxæ; abdomen pinkish yellow, sparsely covered with long hairs pressed flat, most numerous above the spinnerets, oval, two-thirds as wide as long, rather flat, venter paler and hairs more numerous, impossible to see opening of spirale but probably directly in front of spinnerets; colulus wanting; spinnerets protruding a little beyond the abdomen, inferior pair stout, separated by a diameter, basal joint longer than wide, terminal joint a very slender white tube less than half as long as basal joint, half hidden in a mass of black hairs on the lower side, median pair hidden, superior pair with basal joint reduced to narrow ring, terminal joint slightly smaller with an oblique tip extending a little beyond the inferior pair; anal tubercle conical, surrounded by short black hairs; legs, 4-1-2-3, pale yellow sparsely covered with short black hairs, all coxæ and trochanters can be seen beyond the cephalothorax on dorsal side, trochanters not notched, legs spineless except for a pair of apical ventral spines on IV tibia, only little heavier than bristles with a pair of slender bristles between, two claws without teeth on tarsi, legs not scopulate, I pair legs, coxa longest, three 
times as long as wide, trochanter more than half as long as coxa and more slender, femur slightly enlarged and flattened laterally, patella slightly longer than tibia, metatarsus and tarsus equal;

I coxa + troch. fem. pat. tib. metat. + tarsus

1. mm. $\quad 1.5 \mathrm{~mm} .1 . \mathrm{mm} .0 .9 \mathrm{~mm} .1 .5 \mathrm{~mm} .=6 . \mathrm{mm}$. IV pair of coxæ not as long as I pair and slightly longer than trochanter, very long, slender, crooked trichobothria on IV metatarsus and tarsus (these noted and figured by Mr. Banks); epigynum shows only a transverse slit with a chitinized margin above which are a pair of clear oblique depressed oval areas which in life are thickly covered with hairs and on each side widely separated dark circular sacs beneath the skin that are probably the spermatheca.

Neotype \& Texas; Dallas, Bluff View on North West Highway, 16 May 1935. (S. Jones.) 

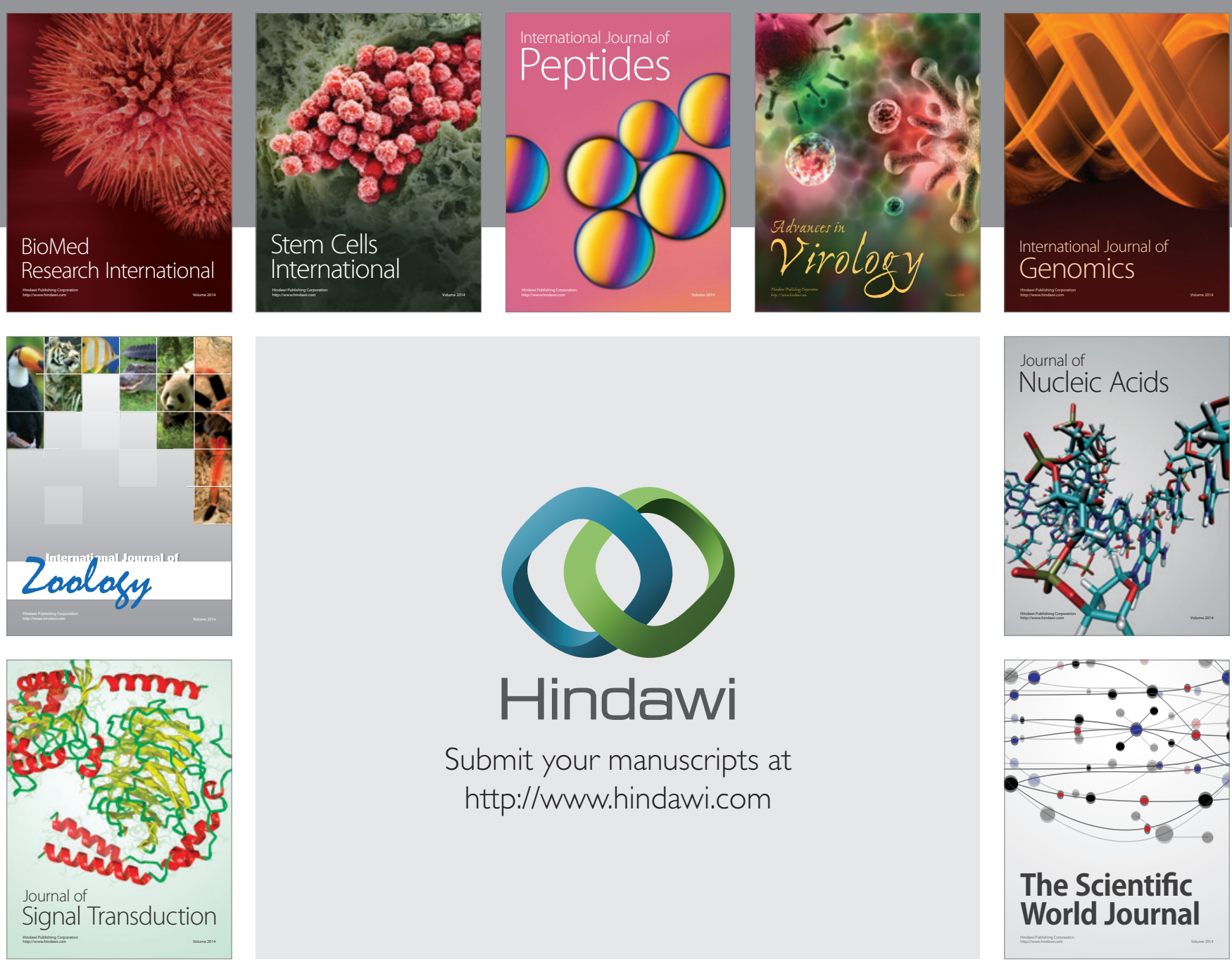

Submit your manuscripts at

http://www.hindawi.com
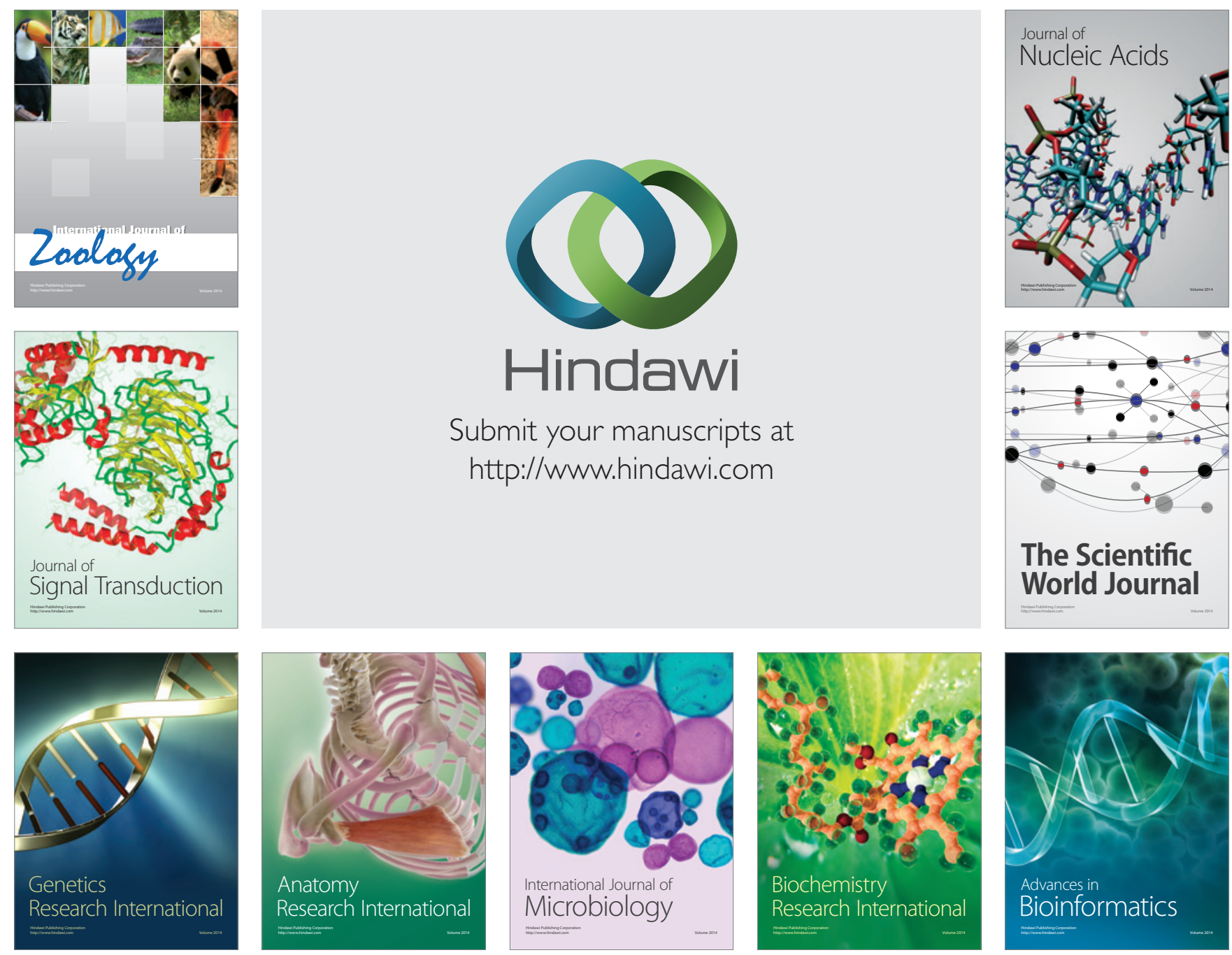

The Scientific World Journal
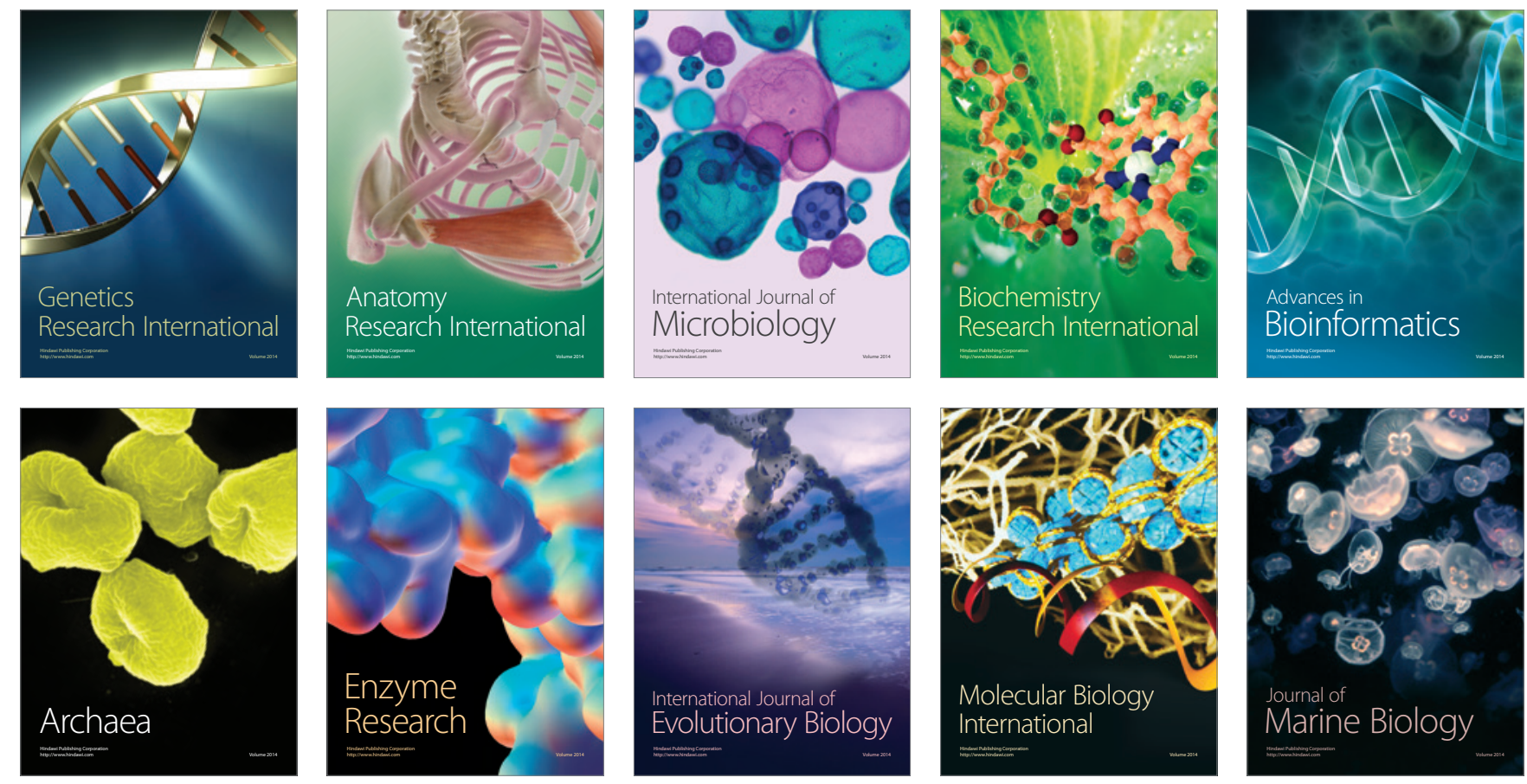